\title{
MIGUILIM, THIAGO E A ESTRADA
}

\section{MIGUILIM, THIAGO AND THE ROAD}

\author{
Juliana Santini \\ UNESP- Universidade Estadual Paulista (FCLAr)
}

\begin{abstract}
RESUMO: Este trabalho utiliza o conceito de cronotopo, discutido por Mikhail Bakhtin, na análise da narrativa literária "Campo Geral", de João Guimarães Rosa, e da narrativa fílmica Mutum, dirigida por Sandra Kogut. Sob esse aspecto, a figura da estrada é tomada como ponto de partida para a observação do modo como se cria a relação entre tempo e espaço em ambas as narrativas.
\end{abstract}

PALAVRAS-CHAVE: Narrativa; Espaço; Tempo; Cronotopo; Estrada.

ABSTRACT: This work uses Bakhtin's concept of chronotope to analyze the literary narrative "Campo Geral", by João Guimarães Rosa, and the filmic narrative Mutum, directed by Sandra Kogut. Therein, the figure of the road is considered as the starting-point for the observation of the way the relationship between time and space is constructed in both narratives.

KEYWORDS: Narrative; Space; Time; Chronotope; Road.

O rapaz, no vão do mundo, assim vocado e ordenado.

João Guimarães Rosa, 2008, p.72

Em texto de 2006, Marilia Amorim (2010) analisa a obra cinematográfica do diretor iraniano Kiarostami e identifica, no seu conjunto, a recorrência de duas figuras: a estrada, onde se dá o deslocamento dos personagens; o carro, que funciona não apenas como veículo do trânsito, mas também como elemento que delimita a dimensão espacial em que se circunscrevem esses sujeitos, sempre imóveis quando se considera a estaticidade de quem, no interior do automóvel, permanece à mercê do movimento realizado pelo veículo. A ambiguidade, aqui, realiza-se no contraste criado entre mobilidade e fixidez: enquanto a imagem do carro representa a metáfora do deslocamento entre espaços distintos, seu interior determina a clausura do sujeito que olha pela janela e, do exterior, conhece apenas a paisagem ou o enquadramento do espaço percorrido.

Nas duas últimas décadas, os road movies colocam em cena a imagem da estrada como cerne da narrativa e ponto de confluência entre a dimensão espacial e temporal da ação, já que agrega o transcorrer do tempo a que se submetem aqueles que caminham à sucessão de espaços que compõem o deslocamento. Em 1999, David Lynch compõe um personagem que, em The straight story, atravessa os Estados Unidos sobre um cortador de grama, buscando a reconciliação com o irmão moribundo. Diários de motocicleta, dirigido 
por Walter Salles em 2004, faz da estrada espaço de formação e reconhecimento daquele que seria o líder da Revolução Cubana. De 2006 é Little Miss Sunshine, cujo enredo se constrói em torno da cruzada da família Hoover, que atravessa o país em uma Kombi, conduzindo a menina Olive para um concurso de beleza. Também de Walter Salles é a adaptação para o cinema do romance norte-americano On the road, de Jack Kerouac, em que a narrativa se projeta do tema da viagem, síntese e desdobramento do título.

Em todos esses casos - e também nos filmes de Kiarostami analisados por Marilia Amorim (2010) -, a composição e o desenvolvimento do personagem dependem da relação intrínseca que estabelecem com a figura da estrada, tanto do ponto de vista de um processo de formação e de reconhecimento desenrolado no interior do trânsito, quanto no que diz respeito à dimensão espacial que, atrelada ao tempo da própria viagem, submete o personagem a territórios outros. É nesse sentido que o conceito bakhtiniano de cronotopo aplica-se à leitura dessas narrativas, uma vez que, para o teórico, cabe ao cronotopo desempenhar o papel de imagem que agrega em si tempo e espaço: "nele é importante a expressão de indissolubilidade de espaço e de tempo (tempo como a quarta dimensão do espaço)." (BAKHTIN, 1998, p.211). Tempo e espaço agregam-se na medida em que o primeiro entranha-se à matéria do segundo, estando a apreensão, a delimitação e a constituição da memória temporal diretamente determinadas por uma ou várias referências espaciais - no limite, como sugere Bachelard (1993) em seu ensaio, o espaço retém o tempo em seus alvéolos.

No desenvolvimento de sua reflexão em torno das relações entre espaço e tempo abarcadas pelo cronotopo nas formas do romance, Bakhtin define a estrada como um cronotopo e situa os motivos do encontro e do reconhecimento como desdobramentos dessa imagem $^{1}$. Encontro e reconhecimento determinam a dimensão do eu e do outro que envolve a experiência espaço-temporal, de maneira que a perspectiva subjetiva dessa articulação faz do cronotopo o ponto que "[...] responde pela forma narrativa e pela visão do mundo e do homem inerente à obra." (NUNES, 1992, p.354).

Partindo dessa visada teórica, os road movies aqui mencionados teriam como elemento que os une a determinação de uma relação de dependência entre tempo e espaço figurativizada pelo cronotopo da estrada que, em termos de significação, impõe que se pense essas narrativas em torno de um processo de reconhecimento - ou de não-reconhecimento, quando se considera a possível negação dos termos - vivenciado por sujeitos que, à procura de algo - o êxito no concurso de beleza por Olive, em The little Miss Sunshine; o perdão e a reparação de um erro em The straight story; o exercício da medicina em Diários de motocicleta; a liberdade, em On the road -, acabam por encontrar o lugar que ocupam no mundo como sujeitos. Na estrada, diferentes instantâneos ou pílulas do tempo que se dissolvem no espaço também apontam para os inúmeros momentos que compõem a história de cada indivíduo.

No conjunto das produções cinematográficas brasileiras, o cronotopo da estrada aparece de maneira recorrente na constituição dos enredos e determina que, à sua observação, some-se uma constatação. Na maioria dos casos, essa figura aparece atrelada ao espaço do sertão, seja delimitado como ponto de partida ou de chegada, seja como território a ser cruzado que, sem origem ou destino, configura-se como matéria mesma da narrativa veja-se que, em Cinema aspirinas e urubus, estreia do diretor Marcelo Gomes, em 2005, o

\footnotetext{
1 “Tem significado particularmente importante a estreita ligação do motivo do encontro com o cronotopo da estrada ("a grande estrada"): vários tipos de encontro pelo caminho. No cronotopo da estrada, a unidade das definições espaço-temporais revela-se também com excepcional nitidez e clareza." (BAKHTIN, 1998, p.223, grifos do autor).
} 
caminho percorrido de povoado em povoado no interior do sertão pontua o encontro do alemão Johann e do sertanejo Ranulpho. E muitos são os exemplos da relação entre as figuras do sertão e da estrada na cinematografia brasileira, alinhando narrativas como Central do Brasil, de 1998, em que a personagem Dora, interpretada por Fernanda Montenegro, parte do Rio de Janeiro em direção ao interior do nordeste à procura da família do menino Josué, e Viajo porque preciso, volto porque te amo, road movie de 2009, dirigido por Marcelo Gomes e Karim Aïnouz, em que a voz do protagonista José Renato narra sua experiência ao atravessar o sertão para que, como geólogo, pudesse verificar a viabilidade de construção de um canal na região.

Nesse conjunto, no filme Mutum, dirigido por Sandra Kogut (2007), a adaptação da novela "Campo geral", de João Guimarães Rosa (1984), também liga o sertão, circunscrito à região que dá título ao longa de 2007, à figura da estrada que, aqui, aparece como espaço de trânsito daqueles que chegam à casa da família do menino Thiago ou dali partem. Também aqui, como no caso dos road movies brasileiros já citados, a estrada configura-se como cronotopo gerador de sentido - Tio Terez parte em direção a um lugar distante quando ameaçado pela desconfiança de seu irmão, que acreditava no adultério da mulher com o vaqueiro. Ocorre, porém, que uma particularidade fundamental se impõe à análise dessa figura em Mutum, qual seja o fato de que o trânsito dos personagens não aparece na narrativa, exceto pela cena final, em que o primeiro plano é construído pela partida de Thiago para a cidade, levado pelo médico generalista que descobrira sua deficiência visual.

Note-se que Mutum não se trata de um road movie, porém, a articulação entre o sertão e a figura da estrada é fundamental à narrativa, já que delimita a oposição entre o espaço em que vive a família e um território outro, almejado pela mãe de Thiago e Felipe e objeto de curiosidade do menino, que anseia por desvendar a beleza do lugar ao mesmo tempo em que questiona, por duas vezes, se ele, a mãe e os irmãos conheceriam o mar. Instaura-se, assim, uma dualidade que se sustenta ao longo de todo o enredo, alternando a estagnação e a fixidez da família à ânsia por outros lugares que, "atrás do morro", escondem a compensação para a vida de miséria no Mutum. A estrada que conduziria a esses lugares funciona como uma imagem que figurativiza o desejo do deslocamento, sempre reafirmado pela personagem da mãe, interpretada por Izadora Fernandes, que reitera em suas falas a clausura daquele espaço e tudo de negativo que a ele é impingido pela imobilidade ${ }^{2}$.

A relação entre sertão e estrada constrói-se, assim, por meio de um contraste no filme de Sandra Kogut: a imobilidade do espaço a que se restringem os personagens e a condição de estagnação a que se submetem opõem-se ao trânsito e ao deslocamento potenciais, impregnados que estão na imagem da estrada. Nesse estado de coisas, interessa a este trabalho observar justamente o modo como se engendra essa relação, observando de que forma estagnação e movimento compõem-se, a partir do cronotopo da estrada, como os limites da existência desses personagens que, tomados da ficção rosiana, têm, na adaptação fílmica, potencializadas as marcas, naqueles que ficam, daqueles que puderam percorrer outras veredas.

\section{Recado do morro}

A novela "Campo Geral”, de João Guimarães Rosa (1984), foi publicada pela primeira vez em 1956, em Corpo de baile, com seis outras narrativas que, a partir da edição

\footnotetext{
${ }^{2}$ Atua de maneira importante para esse contraste entre o Mutum e a cidade a menção ao filho mais velho da família, que não aparece na narrativa justamente porque foi levado por um parente, ainda menino, para ser educado fora do sertão.
}

Disponível em: http://seer.fclar.unesp.br/casa 
de 1964, foram desmembradas em três volumes: Manuelzão e Miguilim, Noites do sertão e No Urubuquaquá, no Pinhém. O sertão mineiro une sob um mesmo eixo de significação as sete histórias, todas permeadas pela organicidade desse espaço, seja em termos das condições materiais que determinam o cotidiano dos personagens, seja no domínio mítico-simbólico, em que os homens do sertão figuram como "ser ladino":

[...] desenvolvem, em relação ao mundo, aquela inteligência que suscita os enigmas de uma vida desconhecida - eles 'desentendem', 'entr'entendem', lendo-os nos ritmos, nos silêncios e nos intervalos, mais do que nos conteúdos e nos preceitos positivos da experiência das suas andanças. (ROSENFIELD, 2006, p.57)

Essa percepção do universo circundante faz de Miguilim um sujeito que, já na infância, primeiro elabora afetivamente as impressões subjetivas da realidade para, então, racionalizá-las por meio da experiência. O mesmo acontece com Dito, irmão mais novo de Miguilim, cuja sabedoria espanta o garoto, que permanece sempre atento a seus conselhos. Exemplares, nesse sentido, são os diálogos estabelecidos entre os dois irmãos, procurando um sentido para o que é certo ou errado, as razões para gostar ou desgostar de alguém, o desvendamento da figura autoritária e violenta do pai. Ocorre, porém, que a trajetória dos dois irmãos e sua relação com o domínio da realidade se realizam de maneira distinta, já que Dito morre ainda jovenzinho, pelas complicações de um ferimento que não foi tratado. A morte de Dito significa, nesse sentido, a interrupção da parceria entre os meninos e, também, o destino distinto de cada personagem: enquanto Dito, conhecedor dos significados do universo e capaz de se posicionar de maneira mais sábia entre os adultos, tem sua infância interrompida pela morte, Miguilim precisa continuar esse caminho, agora na solidão, e aprender a crescer em meio à opressão.

"Campo Geral” (ROSA, 1984) começa com a apresentação de Miguilim e a história de sua primeira viagem para fora do Mutum, quando aos sete anos, foi levado por Tio Terez para ser crismado no Sucuriju. Conhecedor da insatisfação da mãe com o lugar em que a família vivia, o menino retorna exultante, pois um homem, no lugarejo, havia dito que o Mutum era bonito. E Miguilim chega ansioso, conta a novidade para a mãe, que pouco se anima:

A mãe não lhe deu valor nenhum, mas mirou triste e apontou o morro; dizia: - "Estou sempre pensando que lá por detrás dele acontecem outras coisas, que o morro está tapando de mim, e que eu nunca hei de poder ver..." Era a primeira vez que a mãe falava com ele assunto todo sério. (ROSA, 1984, p.14)

A imagem construída nesse trecho, logo no início da narrativa, é emblemática da oposição aqui discutida, já que o Mutum representa, para a mãe, tudo aquilo que não pode ser. O que fica além daquele espaço é barrado pelo morro, que isola o lugar ao mesmo tempo em que estagna a vida e o cotidiano de seus habitantes. Para a mãe, o Mutum está separado do resto do mundo e a imagem do morro atua como parede que isola e, também, lembra incessantemente a existência de um além, território de compensações para o sofrimento de toda uma história de privações. Na narrativa rosiana, a imobilidade é determinada pelo signo do não, enquanto o trânsito permanece apenas como potencialidade. É justamente nesse ponto que se insere a dúvida de Miguilim - o Mutum seria bonito? - e que se sustenta a metáfora da deficiência de visão do garoto, que só consegue enxergar aquele espaço depois de colocar os 
óculos emprestados pelo médico da cidade e, não por acaso, no momento em que ele mesmo se reconhece pronto para deixar o Mutum.

É preciso considerar que, sob essa perspectiva, o próprio olhar se constitui como metáfora estruturante em "Campo Geral" (ROSA, 1984), já que se trata de uma narrativa construída por meio de um narrador heterodiegético - que não participa da diegese como personagem - e que faz uso de uma focalização interna centrada em Miguilim. Em termos de estruturação narrativa, impõe-se a perspectiva subjetiva do personagem e sua visão de mundo passa a funcionar como mediadora na construção do universo diegético, de maneira que ao ponto de vista da criança caberá a instituição de um "filtro quantitativo e qualitativo que rege a representação narrativa" (REIS; LOPES, 1988, p.251). Como sujeito a partir do qual se projeta a regulação do significado, Miguilim tem, na sua experiência, todo o conteúdo a que terá acesso o leitor, o que significa dizer que o Mutum, na narrativa, é o Mutum de Miguilim.

A maneira como o personagem infantil percebe e interioriza os fatos narrados faz com que se tenha a figurativização das restrições impostas à compreensão de uma criança que, naquele espaço, sofre não apenas com a privação material decorrente da condição de pobreza de sua família, mas também - e, dir-se-ia, sobretudo - com a violência que lhe é imposta. Por meio das atitudes e da fala do pai, fica evidente a posição ocupada por Miguilim no domínio familiar: "O que ele quer é ser sempre mais do que nós, é um menino que despreza os outros e se dá muitos penachos. Mais bem que já tem prazo para ajudar em coisa que sirva, e calejar os dedos, endurecer casco na sola dos pés, engrossar esse corpo" (ROSA, 1984, p.115). Contrastam, nesse sentido, a sensibilidade do garoto, que tenta mergulhar minimamente no imaginário da infância - caçar passarinhos, ver o buraco do tatu -, e a dureza imposta pela incompreensão do pai, que o quer semelhante a si mesmo, com o "casco" criado pela rotina de trabalho.

É de violência, portanto, a teia que envolve Miguilim. Se, por um lado, as palavras de seu pai oprimem, rebaixam seu comportamento e atuam em favor da anulação da infância, por outro, o silêncio da mãe corrobora a atitude paterna, aumentando a espessura da cortina que afasta a visão de Miguilim da beleza das coisas: "a violência é uma interrupção, algo que, através de uma punhalada ou pancada ou tiro, retira identidade e subjetividade, posicionando o sujeito em lugar nenhum, deslocando a sua condição" (SILVA, 2012, p.32). Se for tomada como verdadeira a proposição de que a fala atua como agente ou instrumento de violência (SILVA, 2012, p.83), impõe-se a condição marginal de Miguilim diante da família antes mesmo da cena em que o pai o surra depois de o garoto agredir o irmão Liovaldo em defesa de Grivo. Inadequação e exclusão são, assim, os signos que delimitam a experiência de Miguilim no interior do círculo familiar: sem compreender racionalmente as relações dos adultos, apartado da infância como se ela fosse um crime e sendo obrigado a desempenhar um papel ativo ao lado dos homens produtivos da família, o menino adoece e revela, em termos concretos, que não pode se encaixar no papel que lhe é exigido pelo pai.

Tendo saído do Mutum apenas na ocasião de sua crisma, Miguilim é enclausurado pela violência familiar e pela condição de afastamento do mundo imposta pelo ambiente hostil - e distante - em que vive. O olhar permanece restrito a esse espaço e transita entre a dimensão encantatória de momentos em que o personagem infantil liberta-se da opressão e aqueles em que as paredes parecem se fechar e escurecer o mundo. O movimento oscilatório entre essas duas percepções fica evidente quando se toma em conta, por exemplo, o modo como o narrador - sempre revestido pela focalização interna - descreve o caminho percorrido por Miguilim quando fora enviado para campear o gado, aguardando o momento em que o pai se acalmasse: "Beiravam as veredas, verdinhas, o buritizal brilhante. Buritis tão 
altos. As araras comiam os cocos, elas diligenciavam.” (ROSA, 1984, p.126). Essa descrição contrasta com a angústia do menino, ensimesmado em suas coisas, achando que estava tísico, com medo de morrer:

Então ia morrer; carecia de pensar feito já fosse pessoa grande? Suspendeu as mãozinhas, tapando os olhos. Em mal que, a gente carecia de querer pensar somente nas coisas que devia de fazer, mas o governo da cabeça era erroso - vinha era toda ideia das coisas que estão por suceder! Antes as estórias. (ROSA, 1984, p.51)

No interior desse movimento, o Mutum e suas veredas se desenham como uma circunscrição fechada de espaço, definida a partir do isolamento e da clausura. No primeiro caso, a figura da mãe contemplando o morro aponta tanto para um outro espaço que, do outro lado, manda seus recados por aqueles que chegam, quanto para a esterilidade de perspectivas e restrição de conhecimento a que todos ali estavam fadados: “' Que é que é teatro, Mãe?' Miguilim perguntara. - 'Teatro é assim como no circo-de-cavalinhos, quase...' Mas Miguilim não sabia o que o circo era." (ROSA, 1984, p.34). A apreensão do conhecimento e as possíveis relações entre diferentes elementos esbarram na escassez de recursos e naquilo que não chega ao sertão, que é percebido pelos adultos como território de difícil sobrevivência, marcado pela pobreza e pela escassez de recursos - o que teria conduzido, no limite, à morte de Dito: “[...] e o senhor agradeça, eu esteja vindo aqui viver nestas más brenhas, donde só se vê falta de tudo, muita míngua, ninguém não olha p'ra este sertão dos pobres..." (ROSA, 1984, p.42).

A consciência dessa condição institui, no olhar de Miguilim, a percepção de uma força expulsiva, que leva para fora do Mutum aqueles que pensam em construir outra vida. É assim que funciona como metáfora o voo das aves, percebido pelo garoto como a despedida de quem parte: "O gaviãozinho, a gavião-pardo, o gaviãozinho-pintado. A gente sabia esses todos vivendo de ir s'embora, se despedidos." (ROSA, 1984, p.61). Tendo já bebido um "golinho de velhice" (ROSA, 1984, p.77), Miguilim passa a enxergar naqueles que deixaram o Mutum a possibilidade de, também ele, viver em outro espaço. Liovaldo, o irmão mais velho que partira com tio Osmundo Cessim, aparece como realização concreta dessa possibilidade e, se durante a visita ao Mutum, irritara o irmão com os costumes de garoto que não pertencia mais àquele lugar, no momento em que retorna para a cidade deixa o rastro de uma esperança:

Desde muito tempo Miguilim não senhoreava alegria tão espaçosa. Mas não era por causa de ter ficado livre do irmão. Menos por isso, que pelo pensamento forte que formou: o de uma vez poder ir também embora de casa. Não sabia quando nem como. Mas a ideia o suspendia, como um trom de consolo. (ROSA, 1984, p.131)

É justamente nesse ponto que se forma a imagem de um caminho que se pode percorrer, firmando-se como a instituição de um tempo-espaço outro. No que diz respeito à relação de dependência que se estabelece entre as dimensões espacial e temporal na narrativa, até esse momento o que figurava era o domínio da fixidez, delimitado pela opressão e pela carência a que se fez referência. Na relação do menino Miguilim com o Mutum, o espaço é significado pela vivência que se desenvolve entre a roça e a casa, com eventos claramente formadores da consciência do menino: da percepção da época das chuvas ao processo de amadurecimento iniciado com a morte de Dito, é a experiência do personagem que dará 
sentido a essa contaminação do espaço pelo tempo. Desse modo, o cronotopo da estrada não se firma, aqui, como elemento deflagrador do conhecimento ou do autorreconhecimento do personagem, pelo contrário, a estrada atua como na instituição e manutenção de um trânsito apenas possível.

Note-se que o cronotopo da estrada aparece em algumas narrativas rosianas como imagem efetiva de um caminho percorrido por diversos personagens, significando uma trajetória em que diferentes espaços se sucedem a um decurso temporal que se projeta no amadurecimento dos sujeitos semoventes. Em "Sequência", de Primeiras estórias, o filho do seo Rigério persegue uma vaca fugida de um rebanho para devolvê-la a seu dono e, no fim desse caminho, encontra seu primeiro amor; no conto "A hora e vez de Augusto Matraga", inserido no volume Sagarana, também é a estrada que leva o personagem do título, redimido, de volta a sua natureza violenta e ao encontro de sua hora e de sua vez; em "Sarapalha", no mesmo livro, os dois personagens, doentes de malária, aguardam a morte à beira da estrada e revelam os segredos de uma vida. Ao contrário do que ocorre nessas narrativas, em "Campo Geral" (ROSA, 1984) a figura da estrada permanece como potencialidade e determina que o próprio Mutum seja tomado como o ponto em que a cronotipicidade se forma e se concretiza, sendo que da relação do personagem com o espaço se projeta a dimensão temporal desse cronotopo.

É, portanto, no domínio do "tempo vivido" (BACHELARD, 1993) que a experiência de Miguilim se entrelaça ao espaço do Mutum e lhe atribui significado. Restrito ao perímetro da casa e de seus arredores, Miguilim vivencia, primeiro, o sentido da imobilidade e, se a casa representa o enraizamento do sujeito a um espaço, garantindo-lhe aconchego e abrigo ${ }^{3}$ (BACHELARD, 1993), aqui ela é imagem que não protege - que sejam lembradas as orações em dia de chuva para que a habitação não fosse destelhada - e as raízes que ela finca ao chão prendem também os sujeitos a uma condição de isolamento e fixidez. $\mathrm{O}$ sentido da morte - encarado, primeiro, com o medo de estar tísico e, depois, com a doença do irmão Dito -, as dores da violência, o afago da mãe que se transforma em omissão, o possível adultério, a existência do mal e a necessidade de crescer são todos sentidos apreendidos no Mutum, inscrevendo os anos de Miguilim na determinação de uma dimensão humana que, ao mesmo tempo em que recebe daquele território sua experiência subjetiva, demarca no solo o sentido do próprio espaço:

Espaço é o efeito produzido pelas operações que o orientam, o circunstanciam, o temporalizam e o levam a funcionar em unidade polivalente de programas conflituais ou de proximidades contratuais. O espaço estaria para o lugar como a palavra quando falada, isto é, quando é percebida na ambiguidade de uma efetuação, mudada em um termo que depende de múltiplas convenções, colocada como o ato de um presente (ou de um tempo) e modificado pelas transformações devidas a proximidades sucessivas. (CERTEAU, 1994, p.202)

Atuando como cronotopo em "Campo Geral” (1984), o sertão do Mutum forma-se a partir de traços que lhe são atribuídos pela temporalização do espaço, imposta pela experiência de sujeitos que colocam em movimento os vetores potenciais do lugar - não se pode perder de vista que, para Bakhtin (1998), o elemento temporal sobressai em relação ao espaço na composição da cronotipicidade. Estagnação, violência, poder, pobreza e frustração

\footnotetext{
3 "Porque a casa é nosso canto no mundo. Ela é, como se diz amiúde, o nosso primeiro universo. É um verdadeiro cosmos. Um cosmos em toda a acepção do termo.” (BACHELARD, 1993, p.24)
}

Disponível em: http://seer.fclar.unesp.br/casa 
delimitam e dão sentido ao espaço pela dimensão do vivido que, ao mesmo tempo que explora a íntima relação do homem com o sertão - fator que atribui significado ao movimento das aves, à previsão do tempo das chuvas e às cores da natureza -, não deixa de impor à condição humana os limites do próprio espaço. Sujeitos arraigados que são, à família de Miguilim resta o cotidiano do sertão e a vida em potencial representada por outro espaço, o da estrada, que permanece em suspensão: “"Mãe, que é que é o mar, Mãe?' Mar era longe, muito longe dali, espécie duma lagoa enorme, um mundo d'água sem fim. Mãe mesma nunca tinha visto o mar, suspirava. - 'Pois, Mãe, então mar é o que a gente tem saudade?' Miguilim parava." (ROSA, 1984, p.79).

A chegada do Doutor José Lourenço impõe uma mudança de rumos na narrativa. Percebendo a deficiência visual de Miguilim e a dificuldade em enxergar pequenos objetos, o médico coloca seus próprios óculos no rosto do garoto, que passa a ver tudo com nitidez outrora desconhecida. Constituindo-se como um momento epifânico, a cena em que Miguilim vê o Mutum sob as lentes forma-se como metáfora que determina a mudança no olhar do personagem para a realidade. É partir daí, portanto, que aceitar o convite para partir com o médico, ganhar um par de óculos e frequentar a escola representa não apenas enxergar o Mutum com um distanciamento que permite reconhecer sua beleza, mas também, e sobretudo, reger-se por um outro espaço e por um outro tempo: agora, Miguilim calçava as botinas para repisar a estrada, cronotopo que se abre como o caminho de uma nova vida, lugar a ser temporalizado.

\section{O Mutum era bonito! Agora ele sabia. ${ }^{4}$}

Desde 1965, com o filme A hora e a vez de Augusto Matraga, dirigido por Roberto Santos, o cinema assiste a muitas adaptações das narrativas rosianas. Somente na década de 90 do século $\mathrm{XX}$, as telas viram as páginas de Rosa em sete produções, entre longas, curtas e documentários, dos quais se destacam A terceira margem do rio, de Nelson Pereira dos Santos, lançado em 1994. Em 2007, o filme Mutum, dirigido por Sandra Kogut, marca a transposição da novela "Campo Geral" para uma linguagem que, simultaneamente, cola-se ao imaginário e à linguagem de João Guimarães Rosa e suplanta as determinações impostas pelo domínio da adaptação por meio de uma expansão do universo representado. Esse efeito é obtido pelo deslocamento obtido com a mudança no nome dos personagens, já que, no filme, os personagens infantis Miguilim e Dito passam a se chamar Thiago e Felipe, respectivamente. Essa mudança poderia ter menos importância se fosse desconsiderado o fato de que esses são os nomes dos meninos que interpretam os dois garotos, ambos atores não profissionais, escolhidos pela diretora entre crianças de escolas rurais da região sul de Minas.

A opção por moradores da região e pela locação das cenas em uma fazenda que manteve seu cotidiano de trabalho ao longo das filmagens garante ao longa um efeito de real que o liga a um contexto distinto daquele em que se centra a narrativa rosiana, em movimento aparentemente restritivo que acaba por ampliar os domínios da ação, inserindo-a também em um tempo outro. Ao tratar dessa opção pelo real, Sandra Kogut afirma que

MUTUM é o resultado de um longo trabalho de preparação, no qual o elenco viveu junto na fazenda onde a história acontece. Aos poucos formaram uma família, antes mesmo do início da filmagem. Dividiram uma experiência de vida, diretamente ligada à história contada no filme. Ninguém leu o roteiro. Tudo foi transmitido oralmente e o trabalho de atuação se construiu a partir

\footnotetext{
${ }^{4}$ ROSA, G. Manuelzão e Miguilim (Corpo de baile). 9.ed. Rio de Janeiro: Nova Fronteira, 1984, p.142.
} 
da proximidade entre a vida deles e a de seus personagens. (KOGUT, $2012^{5}$, grifos nossos)

O resultado é uma linguagem que articula o erudito - apreendido a partir da relação direta com a novela "Campo geral" (ROSA, 1984) - a uma dicção popular que em muito aproxima o filme do projeto estético rosiano, também ele afinado a essa articulação. Se a dicção popular alinha a narrativa fílmica à literária, as estruturas de ambas mostram-se semelhantes na medida em que a produção cinematográfica propõe soluções para que se mantenham semelhantes - ao menos do ponto de vista do sentido que projetam - diferentes instâncias narrativas que se compõem nas páginas da novela. É o caso, por exemplo, da unidade espacial e da linearidade temporal do enredo, que atribuem a "Campo geral" (ROSA, 1984) uma narratividade muito semelhante ao ritmo que caracteriza as histórias orais.

Também em Mutum (KOGUT, 2007) a perspectiva narrativa é construída por meio da focalização interna no personagem infantil - agora Thiago -, o que se verifica, em termos concretos, na organização reiterada de planos em que o menino, de costas para a câmera, é colocado em primeiro plano, enquanto aquilo que seus olhos veem - e, no limite, como seus olhos veem - desenha o segundo plano de um determinado enquadramento. Impõe-se, aqui, o mesmo olhar infantil, ao qual se nega o acesso ao universo adulto, e a mesma restrição de campo que organiza as informações diegéticas na narrativa literária. Ocorre, porém, que mesmo a coincidência na estruturação das instâncias narrativas não permite que se olhe para a realização cinematográfica como um mero decalque dos significados que se projetam de "Campo Geral" (ROSA, 1984). Para além da relação direta com o real, obtida por meio da opção por encenar os personagens com moradores da fazenda em que as cenas foram rodadas, como já se discutiu, há que se notar que a mesma circunscrição fechada de espaço adquire significados distintos quando se tomam, lado a lado, novela e filme.

Enquanto em "Campo Geral” (ROSA, 1984) a estagnação dos personagens é reiterada e contrasta com uma perspectiva de mobilidade apenas potencialmente referida na figura da estrada, em Mutum (KOGUT, 2007) essa potencialidade concretiza-se em signos recorrentes que tornam mais próxima a possibilidade do trânsito. Isso fica evidente quando se leva em conta, por exemplo, a sinopse oficial do filme:

Mutum quer dizer mudo. Mutum é uma ave negra que só canta à noite. $\mathrm{E}$ Mutum é também o nome de um lugar isolado no sertão de Minas Gerais, onde vivem Thiago e sua família. Thiago tem dez anos e é um menino diferente dos outros. É através do seu olhar que enxergamos o mundo nebuloso dos adultos, com suas traições, violências e silêncios. Ao lado de Felipe, seu irmão e único amigo, Thiago será confrontado com este mundo, descobrindo-o ao mesmo tempo em que terá de aprender a deixá-lo. ${ }^{6}$

Situando o domínio do sertão em termos topográfico e imaginário - espaço em Minas Gerais, que também é o mundo e faz referência a uma ave -, a sinopse aponta para alguns elementos fundamentais da composição fílmica: à perspectiva narrativa centrada em Thiago soma-se a indicação de que o protagonista partirá para outro espaço, tendo, antes,

\footnotetext{
${ }^{5}$ Depoimento disponível em: http://www.mutumofilme.com.br/notas.htm, sem numeração de página. Acesso em $15 / 08 / 2012$.

${ }^{6}$ Sinopse disponível em: http://www.mutumofilme.com.br/sinopse.htm, sem numeração de página. Acesso em $15 / 08 / 2012$.
} 
descoberto o Mutum e se preparado para a viagem. Ao iniciar a sinopse com as possíveis significações da palavra que dá título ao filme, destaca-se a ambiguidade da relação que o personagem Thiago estabelecerá com esse território: delimitando um espaço fechado, mas simultaneamente se ampliando à dimensão do mundo, mutum - que, diga-se, é um palíndromo e em sua forma impõe duas direções que apontam para um mesmo centro - é também ave do sertão, o que não deixa de fazer referência a voos possíveis.

E o filme de Sandra Kogut (2007) trabalhará a reiteração desse movimento - a relação entre Mutum e o mundo, entre o estático e o móvel, entre a estagnação e o trânsito ao longo de toda a sua constituição. A narrativa inicia-se com Thiago e Tio Terez chegando ao Mutum, montados em um cavalo - uma referência à viagem que o menino fizera para se crismar, no Sucuriju -, em estrada que corta o sertão.

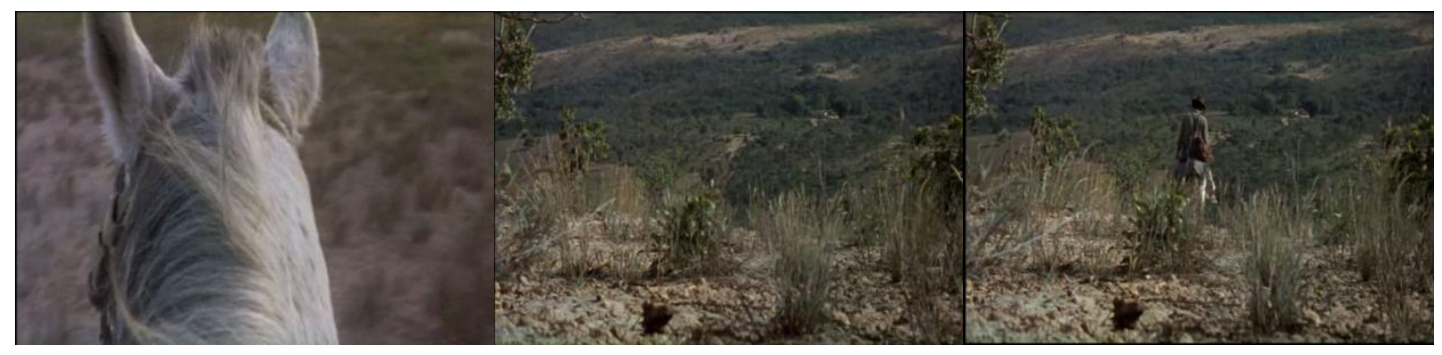

Sequência 1

A sequência acima deixa claros a chegada e o modo como o princípio do filme explora elementos que se tornarão centrais na composição da narrativa. Ao enquadramento em que se tem a pequena estrada, avistada ao longe entre a vegetação rasteira e o solo do sertão, somam-se as figuras humana - Tio Terez, acompanhado de Thiago - que ocupam justamente o centro da cena. De frente para a estrada, os personagens ditam a direção do deslocamento: como se de fora para dentro, percorrem o caminho que leva ao Mutum, tendo um morro ao fundo - aquele atrás do qual a mãe de Miguilim imagina o que se passa do outro lado do mundo? Aqui, o cronotopo da estrada começa a se esboçar, metaforizando, na imagem da volta para casa, o caminho que Thiago percorrerá quando estiver, enfim, pronto para deixar o Mutum.

Discutindo as narrativas de João Guimarães publicadas entre 1946 e 1956 - de Sagarana a Grande sertão: veredas, portanto -, Benedito Nunes observa no motivo do trânsito um traço recorrente da poética rosiana, situando seus desdobramentos como elementos que, no conjunto, constroem uma espécie de isotopia da andança:

Daí o alternado movimento do ir e do vir, do longe e do perto, do transponível e do intransponível, do caminho e do descaminho, da vereda e do Sertão, da entrada e da saída, do começo e do fim de um percurso, da chegada e da partida, que constitui a dialética da viagem, regente da forma do enredo romanesco, na acepção ampla desta última palavra, como síntese de acontecimentos narrados. (NUNES, 1998, p.254-255)

Na sequência que dá início a Mutum (KOGUT, 2007), o fim do percurso é justamente a chegada ao espaço da imobilidade, em que a família de Thiago aguarda seu retorno, com os pequenos ansiosos por novidades. Nos limites da casa, a focalização interna no garoto mantém a mesma atmosfera de opressão e de interdição ao mundo infantil já observada na narrativa rosiana. Ocorre, porém, que, no filme, o que permanecia como 
potencialidade em "Campo Geral" (ROSA, 1984) ganha força por meio de sequências em que a estrada ocupa posição de destaque. É o que se verifica no intervalo que se dá entre o convite do médico da cidade, para que Thiago o acompanhe, e o momento em que a mãe comunica ao garoto a possibilidade de construir uma nova vida, depois de ganhar óculos, estudando e conhecendo um universo outro.

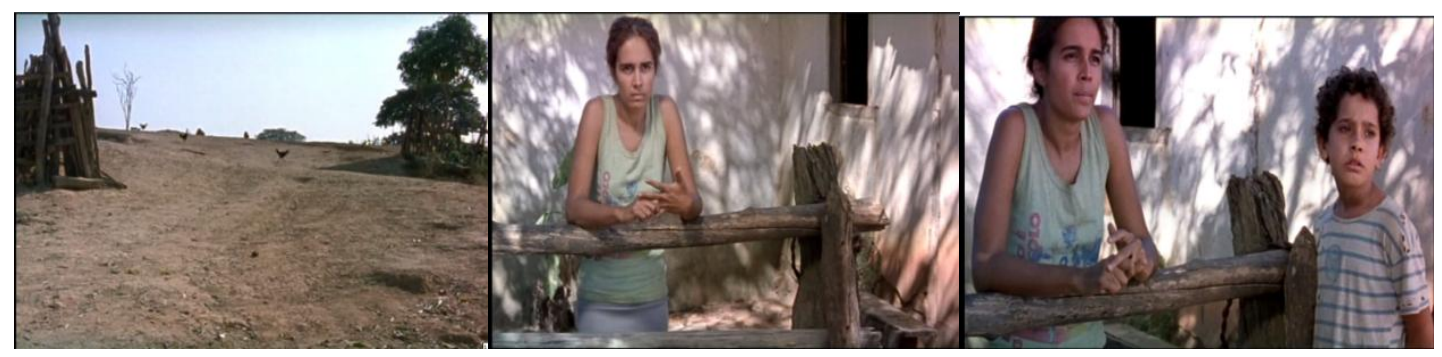

Sequência 2

No momento em que a perspectiva narrativa é transferida para o olhar da mãe de Thiago, a imagem focalizada é justamente a da estrada, que agora conduz para fora do Mutum, representando o caminho que o garoto percorreria junto com o médico. Em silêncio, mirando a estrada, a mãe faz da ausência de palavras - justamente o que delimita todo o universo sertanejo que cerca Thiago - a marca dos sucessivos espaços e tempos que, diante de seus olhos, aguardam o menino: agora, o recado que a mãe ouve é o da estrada. Na sequência, Thiago e a mãe olham para o mesmo lugar - no sentido de território a ser temporalizado pela experiência, como quer Michel de Certeau (1994) - e, por alguns segundos, compartilham de um mesmo tempo, aquele em que o adulto e a criança se encontram.

O movimento realizado pela focalização narrativa, nesse ponto, impõe uma leitura que conduz para o desfecho do enredo: como imagem, figura do motivo do trânsito, a estrada aparece como cronotopo que, enfim, concretiza-se no interior da narrativa e agrega as dimensões temporal e espacial que determinarão os destinos do personagem. Na sequência seguinte, montada a partir da cena que encerra o filme, a focalização volta para Thiago que, sozinho, se responsabilizará por mirar o seu próprio caminho.

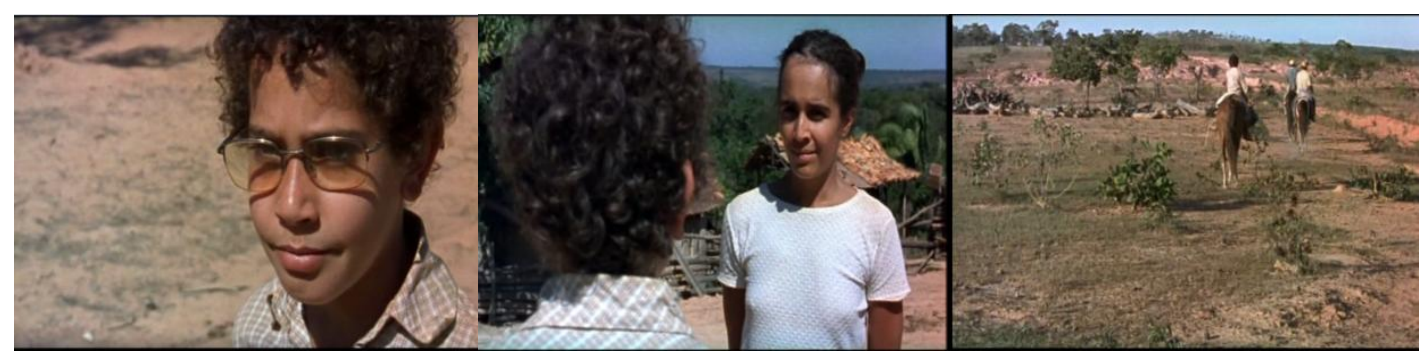

Sequência 3

Novamente com os óculos do médico, Thiago olha para o Mutum e sorri, como quem reconhece a beleza do lugar - aquilo que foi sua dúvida ao longo da infância. No enquadramento seguinte, o posicionamento do menino de costas para a câmera, à esquerda e diante da figura da mãe, faz com que o sorriso da mulher seja, no limite, o modo como o filho vê o semblante de sua mãe antes de montar em seu cavalo e iniciar a trajetória pela mesma estrada que, no início da narrativa, o trouxe para o Mutum ao lado de Tio Terez. No último 
enquadramento, Thiago aparece montado em seu próprio cavalo - e não mais na companhia de um adulto, como ocorrera no princípio - e seguindo os dois homens da cidade, rumo à estrada que se abre em sua frente. Nesse momento, institui-se um campo de visão ambíguo, já que, na posição em que se encontra o garoto, tem-se, simultaneamente, o olhar daqueles que, permanecendo no Mutum, acompanham a partida de mais um de seus habitantes - o irmão mais velho foi o primeiro -, enquanto também se impõe outra perspectiva, a do próprio Thiago, olhando para frente e para o início do trajeto que determinará sua transformação. Aqui, inicia-se o cantar de um sertanejo, em trova popular que tematiza a partida do sertão e anuncia o fim da narrativa - justamente quando começa a vida de Thiago.

\section{Uma outra estória}

A epígrafe que abre este artigo diz respeito ao movimento do protagonista do conto "Sequência", de João Guimarães Rosa (2008, p.72). No meio do sertão, na estrada, seguindo uma vaca, o filho de Seo Rigério para por um momento e se pergunta o porquê daquilo tudo. E o rapaz continua no rastro do animal, sem saber a razão. Para Benedito Nunes (1994), essa é a condição de muitos dos personagens rosianos, que reduplicam o trânsito das aves sertanejas, das estrelas e do céu em seus passos. Na novela "Campo Geral" (ROSA, 1984), esse movimento não é narrado, mas a possibilidade do trânsito permanece em suspenso como mudança em potencial na vida de Miguilim, que verá o "vão do mundo" abrir diante de si apenas no momento em que a narrativa se encerra.

O filme de Sandra Kogut (2007) coloca em cena a imagem que marcará o destino de seu personagem Thiago, de modo que ganham ênfase as possibilidades germinadas na espacialidade da estrada. É justamente nesse sentido que se pode dizer que, na narrativa fílmica, o cronotopo da estrada concretiza-se nos termos em que Bakhtin (1998) o define. O que era uma presença in absentia na novela de João Guimarães Rosa ganha forma no filme e passa a agregar as dimensões espacial e temporal vivenciadas pelo personagem MiguilimThiago. Se a estagnação e a imobilidade marcam o espaço do Mutum tanto em uma quanto em outra narrativa, também é verdade que a constituição do cronotopo impõe ao filme o signo do movimento - que se desdobra em reconhecimento -, seja na chegada de Thiago e Tio Terez que dá início à narrativa, seja na partida de Thiago no enquadramento que encerra o longa.

"Campo Geral" (ROSA, 1984) termina no momento em que Miguilim reconhece que o Mutum é bonito, colocando os óculos pela segunda vez. Nesse ponto, quase que epifânico, o personagem está pronto para sair de casa e enfrentar a estrada, que não chega a ser mencionada na cena final, desenhada pelos abraços e pelas despedidas, pelos doces colocados na algibeira do garoto, pelo canto de Papaco-o-Paco. Em Mutum (KOGUT, 2007), torna-se emblemático o fato de que a estrada põe fim à narrativa. Com o olhar de Thiago avistando o caminho que tem diante de si e, ao mesmo tempo, sendo observado por aqueles que ficam, inicia-se uma caminhada que só pode ser empreendida por quem já havia encontrado seu lugar no espaço que habitava. Nos dois casos, reconhecer a beleza do Mutum é o que dá ao personagem infantil o bilhete de passagem para um novo espaço e para a construção de outros tempos. Também em ambas as narrativas uma outra possível história se abre. No filme, com as margens da estrada que se desenha, essa história pode ser visualizada, quem sabe, nos contornos de um road movie. 


\section{REFERÊNCIAS}

AMORIM, M. Cronotopo e exotopia. In: BRAITH, B. (Org.). Bakhtin: outros conceitoschave. São Paulo: Contexto, 2010. p.95-114.

BACHELARD, G. A poética do espaço. São Paulo: Martins Fontes, 1993.

BAKHTIN, M. Questões de literatura e de estética (a teoria do romance). 4.ed. São Paulo: Editora da UNESP, 1998.

CERTEAU, M. de. A invenção do cotidiano: artes de fazer. Petrópolis: Vozes, 1994.

KOGUT, S.

MUTUM. Direção: Sandra Kogut. Fotografia: Mauro Pinheiro Jr. [s.1]: Videofilmes, 2007. 1DVD (95min.), NTSC, color.

NOTAS DA DIRETORA. Disponível em: http://www.mutumofilme.com.br/notas.htm. Acesso em 12/08/2012.

NUNES, B. Crivo de papel. 2.ed. São Paulo: Ática, 1998.

. Tempo. In: Palavras da crítica. JOBIM, J. L. (Org.). Rio de Janeiro: Imago, 1992. p.343-365.

REIS, C.; LOPES, A. C. M. Dicionário de teoria da narrativa. São Paulo: Ática, 1988.

ROSA, J. G. Campo Geral. In: Janeiro: Nova Fronteira, 1984. p.11-142.

Sequência. In:

Primeiras estórias. Rio de Janeiro: MEDIAFashion, 2008.

p.70-75. Coleção Folha Grandes Escritores Brasileiros. v.11.

ROSENFIELD, K. H. Desenveredando Rosa: a obra de J. G. Rosa e outros ensaios rosianos. Rio de Janeiro: Topbooks, 2006.

SILVA, D. do N. e. Pragmática da violência: o Nordeste na mídia brasileira. Rio de Janeiro: 7 Letras; FAPERJ, 2012.

SINOPSE. Disponível em: http://www.mutumofilme.com.br/sinopse.htm. Acesso em 12/08/2012. 